\title{
Using a Parameterization of a Radiative Transfer Model to Build High-Resolution Maps of Typical Clear-Sky UV Index in Catalonia, Spain
}

\author{
Jordi Badosa, Josep-Abel GonzÁlez, ANd Josep CAlbó \\ Departament de Física, Grup de Física Ambiental, Universitat de Girona, Girona, Spain \\ Michiel VAN WeELE \\ Royal Netherlands Meteorological Institute (KNMI), De Bilt, Netherlands \\ RichARD L. MCKeNZIE \\ National Institute of Water and Atmospheric Research (NIWA), Lauder, New Zealand
}

(Manuscript received 5 May 2004, in final form 22 November 2004)

\begin{abstract}
To perform a climatic analysis of the annual UV index (UVI) variations in Catalonia, Spain (northeast of the Iberian Peninsula), a new simple parameterization scheme is presented based on a multilayer radiative transfer model. The parameterization performs fast UVI calculations for a wide range of cloudless and snow-free situations and can be applied anywhere. The following parameters are considered: solar zenith angle, total ozone column, altitude, aerosol optical depth, and single-scattering albedo. A sensitivity analysis is presented to justify this choice with special attention to aerosol information. Comparisons with the base model show good agreement, most of all for the most common cases, giving an absolute error within \pm 0.2 in the UVI for a wide range of cases considered. Two tests are done to show the performance of the parameterization against UVI measurements. One uses data from a high-quality spectroradiometer from Lauder, New Zealand [ $45.04^{\circ} \mathrm{S}, 169.684^{\circ} \mathrm{E}, 370 \mathrm{~m}$ above mean sea level (MSL)], where there is a low presence of aerosols. The other uses data from a Robertson-Berger-type meter from Girona, Spain $\left(41.97^{\circ} \mathrm{N}\right.$, $2.82^{\circ} \mathrm{E}, 100 \mathrm{~m} \mathrm{MSL}$ ), where there is more aerosol load and where it has been possible to study the effect of aerosol information on the model versus measurement comparison. The parameterization is applied to a climatic analysis of the annual UVI variation in Catalonia, showing the contributions of solar zenith angle, ozone, and aerosols. High-resolution seasonal maps of typical UV index values in Catalonia are presented.
\end{abstract}

\section{Introduction}

Disseminating the actual levels of UV radiation has recently become very common so that the population can be informed and take precautionary measures against the known harmful effects that this radiation can produce on human beings (e.g., Vanicek et al. 2000). For this purpose, the UV index (UVI) - an estimation of the UV levels that are important for the effects on human skin - is the magnitude that is commonly used. It is derived from the erythemal UV irradiance (UVE), which is the integration of the monochromatic UV irradiance (280-400 nm) weighted by the Commission Internacionale de l'Eclairage (CIE) spectral action function (McKinlay and Diffey 1987). UVI is

Corresponding author address: Jordi Badosa, Grup de Física Ambiental, Departament de Física, Universitat de Girona, Escola Politècnica Superior, Campus Montilivi, EPS II, 17071 Girona, Spain.

E-mail: jordi.badosa@udg.es a unitless magnitude that is defined as 40 times UVE (expressed in watts per meter squared).

UVI commonly takes values from 0 to 16 (reaching the maximum in summer midday) but in some regions and for particular conditions it can reach up to 20 units. Larger UVI values correspond to more harmful UV radiation for human beings. The overall effect depends on the exposed parts of the body, their sensitivity to UV radiation, and the dose received (information available online at http://www.who.int/).

The use of UVI maps is necessary to entirely cover a particular region. However, there is usually a lack of high-density spatial UVI measurements to represent all the territory. So, other sources (such as meteorological ground- and satellite-based information) and methods (such as empirical algorithms and radiative transfer modeling) usually become necessary.

Some authors have solved the lack of UVI groundbased measurements by combining UVE and total solar irradiance measurements, because the latter are more often measured than the former. Bodeker and McKen- 
zie (1996) used radiative transfer modeling and empirical relations between these two magnitudes to develop an algorithm that retrieves UVI for all cloud conditions, considering total irradiance, total ozone column (TOZ), altitude, surface pressure, temperature, and humidity measurements. This algorithm is currently used in the National Institute of Water and Atmospheric Research (NIWA) UV Atlas project to produce maps and time series of UVI over New Zealand (additional information is available online at http://www.niwa.cri. $\mathrm{nz} /$ services/uvozone/atlas). Schmalwieser and Schauberger (2001) established relationships between UVE measurements that are available from 9 sites and total irradiance measurements that are available from 39 other sites in Austria to cover the whole country. Cloud effects were also included through relationships between UVE and total irradiance. For the visualization of the data, daily maps of noontime UVI were then created with a spatial resolution of approximately $1 \mathrm{~km}$. Fioletov et al. (2003) found a statistical relationship between total irradiance and UVE, considering total ozone, snow cover, dewpoint temperature, and altitude. They applied this algorithm to 45 stations with total irradiance measurements in Canada to estimate a UVI climatology. Different types of statistical maps were produced, such as monthly mean daily UVI, mean noontime UVI, 95th percentile of the noontime UVI, and hourly mean UVI.

Some other studies have produced UVI maps based on radiative transfer modeling and using satellite measurements as input. For example, Verdebout (2000) presented a method to produce UVI maps over Europe with $0.05^{\circ}$ spatial resolution and half an hour of potential temporal resolution. The method is based on a lookup table generated with a radiative transfer model, whose inputs are solar zenith angle (SZA), total ozone, cloud optical thickness, near-surface horizontal visibility, altitude, and surface UV albedo.

Concerning satellite-derived information, daily UV dose maps and values are available worldwide from the Total Ozone Mapping Spectrometer (TOMS) (see information online at http://toms.gsfc.nasa.gov). The algorithm developed for these calculations uses a table of solutions of the radiative transfer equation. This table also serves for TOMS total ozone column retrievals and takes into account cloud effect (assuming that cloud conditions at noontime are representative for the whole day) and surface albedo, using a method to assess the probability of snow presence.

Recently, Schmalwieser et al. (2002) presented a model based on ground-based spectral measurements that calculates the spectral irradiance for 16 wavelengths between 297.5 and $380 \mathrm{~nm}$ and used this model

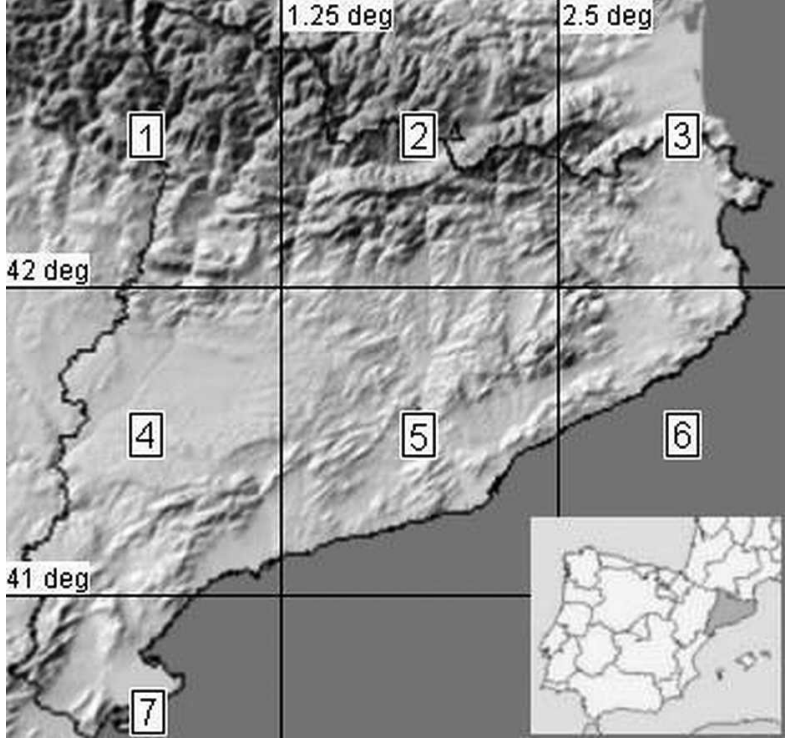

FIG. 1. Topographic map of Catalonia with $1-\mathrm{km}$ resolution. The lower-right square shows where Catalonia is situated in the Iberian Peninsula. Latitude and longitude lines are also shown. The numbers in the boxes indicate the cells of Earth Probe TOMS.

to predict UVI worldwide (information online at http:// i115srv.vu-wien.ac.at/uv_online.htm). The model takes into account solar zenith angle, altitude, and forecasted total ozone. Allaart et al. (2004) developed an empirical algorithm to predict UVI (hereinafter called ALUVI) that takes into account solar zenith angle, total ozone, and altitude. Noontime-predicted worldwide UVI maps based on the assimilated Scanning Imaging Absorption Spectrometer for Atmospheric Chartography (SCIAMACHY) total ozone measurements are presented for a given day and the following 4 days at the Tropospheric Emission Monitoring Internet Service (TEMIS) Web site (available online at http://www .temis.nl/uvradiation).

The present work is directed to retrieve seasonal maps of typical UVI under clear-sky and snow-free conditions for Catalonia, in the northeast of Spain. In this relatively small area $\left(32000 \mathrm{~km}^{2}\right)$ there is a complex topography, from a coastal line facing to the Mediterranean Sea to the Pyrenees Mountains, with a maximum altitude of $3143 \mathrm{~m}$ (see Fig. 1). Because of this, Catalonia experiences large meteorological and climatic variability, giving rise to many different climatic conditions within a radius of few kilometers; this diversity also allows people to practice very different activities, from sun bathing on the beach to mountain hiking and skiing, all of which have important potential exposures to UV radiation.

Thus, to have a complete characterization of the meteorological and climatic phenomena in Catalonia a 
large density of measuring sites is required. Currently, there are only five sites where erythemal UV irradiance is measured in Catalonia, all of which have a short data record. A possible alternative could be to retrieve typical UVI values based on radiative transfer calculations. However, on the one hand, we want high spatial resolution coverage (which involves an important computational cost) and, on the other hand, no accurate highly resolved information about some input variables, such as the aerosol information, is available. So it seems reasonable to simplify models through their parameterization, make assumptions, and then also allow fast calculations. The parameterization here presented [named the Parameterization of the Tropospheric Ultraviolet and Visible (PTUV) radiative transfer model] considers SZA, TOZ, altitude ( $z$ ), aerosol optical depth at 368 $\mathrm{nm}\left(\mathrm{AOD}_{368}\right)$ and aerosol single scattering albedo (SSA) as input parameters.

The PTUV model is introduced in section 2, including a discussion about the base model used, the choice of the parameters, the mathematical structure of the formula, and, finally, comparisons with the base model. In section 3, the parameterization is tested by comparing it with UVI measurements from two sites-one using high spectral UV measurements and the other from a Robertson-Berger-type meter. Special attention is paid to the aerosol effects and how the aerosol information is introduced to the model. In section 4 the annual variations of SZA, TOZ, and $\mathrm{AOD}_{368}$, and how they affect the annual UVI variation, is analyzed and the process of generating seasonal UVI maps for Catalonia is explained.

\section{Methodology}

\section{a. Radiative transfer calculations}

The Tropospheric Ultraviolet and Visible (TUV) Radiative Transfer Model (Madronich 1993), version 4.1, is the base model for the parameterization. The package, which consists of a group of routines written in FORTRAN77, is available online (see http:// www.acd.ucar.edu/TUV/). TUV is a multilayer model that solves the radiative transfer equation by two streams or discrete ordinates (DISORT) with $n$ streams. Versions with pseudospherical corrections are available. Because only plane irradiances are studied, the DISORT code with eight streams and pseudospherical corrections is used in this work.

The TUV default options have been considered here, except for changing the default aerosol optical depth fixed values from Elterman (1968) for a new aerosol profile described below. The spectral range considered
TABLE 1. Values considered for SZA, TOZ, $z, \mathrm{AOD}_{368}$, and SSA used to retrieve and validate the parameterization; this leads to 15120 different cases. The sea level $\mathrm{AOD}_{368}$ range is written here because this range is altitude dependent [see Eq. (2)]. For alpha and $g$, constant values are considered.

\begin{tabular}{ll}
\hline \hline Parameter & \multicolumn{1}{c}{ Values considered } \\
\hline SZA & $0^{\circ}, 10^{\circ}, 20^{\circ}, 30^{\circ}, 40^{\circ}, 50^{\circ}, 60^{\circ}, 70^{\circ}, 80^{\circ}$ \\
TOZ & $200,250,300,350,400,450,500 \mathrm{DU}$ \\
$z$ & $0,1,2,3,4 \mathrm{~km}$ \\
AOD $_{368}$ & $0,0.1,0.2,0.4,0.6,0.9,1.2,1.5$ \\
SSA & $0.6,0.7,0.8,0.9,0.95,1$ \\
Alpha & 1.4 \\
$g$ & 0.7 \\
\hline
\end{tabular}

for all UVI calculations was $280-400 \mathrm{~nm}$, with a wavelength increment of $1 \mathrm{~nm}$.

\section{b. Parameters considered}

Although the application discussed here is only for the small region of Catalonia, the parameterization was developed in order to be able to explain a wide range of conditions under cloudless skies. Because of this, SZA, TOZ, $z, \mathrm{AOD}_{368}$, and SSA were taken with wide ranges (as shown in Table 1).

However, some particular situations are omitted from the coverage of this study. Particular surface types with large albedo, such as snow and sand, are not taken into account here. It is known that the effect of surface albedo on UVI depends on the topography, type of soil, and also the turbidity of the surroundings (e.g., Madronich 1993; Madronich et al. 1994); this makes it difficult to find the actual surface albedo values that represent each site at each moment. Weihs et al. (2002) considered three inversion methods to retrieve surface albedo from UV measurements in spring in Germany and surrounding areas. They found differences of \pm 0.15 in the albedo that is retrieved with the three methods that lead, according to the authors, to an uncertainty in the UV irradiance calculation [in ultraviolet B (UVB) and ultraviolet $\mathrm{A}$ (UVA)] of approximately $\pm 3 \%-5 \%$. In our study, there is a lack of information about climatic estimations of surface albedo and snow cover for Catalonia; because of this, considering large-albedo cases would be too subjective and, thus, nonrepresentative of the real situation. Most common surfaces have surface albedo less than 10\% (e.g., Madronich 1993). In this work, a typical value of $5 \%$ is set constant for all the UV calculations.

Also, the conditions of very high turbidity have not been considered for the retrieval of PTUV because these situations are rare (especially in Catalonia) and to parameterize them would add extra complexity.

In the following, the five parameters and their ranges 
considered for the parameterization elaboration are discussed.

\section{1) SolAR ZENITH ANGLE}

Solar zenith angle affects both the optical path through the atmosphere and the angular distribution of solar radiation. Actually, SZA is the main factor affecting UVI. For the parameterization, the range of $0^{\circ}-80^{\circ}$ of SZA is considered.

\section{2) Total ozone Column}

The role that ozone plays in diminishing UV radiation is well known (e.g., Lenoble 1993; Herman et al. 1999). Total ozone column is the most important parameter to describe this effect. For the parameterization development, the range of 200-500 Dobson units (DU) is considered. One Dobson unit is the equivalent of $2.69 \times 10^{16}$ molecules of ozone per centimeter. Concerning the vertical ozone profile, TUV default information (from U.S. Standard Atmosphere, 1976) is assumed to be representative. However, the influence of the vertical distribution of ozone on UVI is much less important than that of TOZ. Through modeling with TUV it was calculated that UVI was increased by up to $8 \%$ (for SZA conditions from $0^{\circ}$ to $80^{\circ}$ ) when a midlatitude ozone profile was replaced by a tropical profile, which is an extreme scenario.

\section{3) Altitude}

As altitude increases, a portion of atmosphere is left underneath; this reduces radiation extinction and, thus, causes an increase in UVI. For an imaginary case with an infinite snow-free flat surface, an increase of about $5.5 \% \mathrm{~km}^{-1}$ in UVI would be expected for clear skies; this is what we found with TUV modeling from 0 to 1 $\mathrm{km}$, with SZA of $30^{\circ}$ and TOZ of $350 \mathrm{DU}$. The change of SZA and TOZ separately can slightly affect this value, up to $\pm 0.3 \%$. This is in agreement with experimental findings from McKenzie et al. (2001a). When the effect is calculated for 3-4 km of altitude, a smaller percentage, $4.8 \%$, is found due to the nonlinear air density vertical distribution. However, these considerations are of minor importance compared with what changes in atmospheric and surface properties can induce. Above sea level, ground surfaces are often mountainous, sometimes being semi-snow covered, and the atmosphere always contains some pollution that varies vertically, horizontally, and temporally. Because of this, the observed altitude effect varies greatly from place to place, as has been reported by several authors. Blumthaler et al. (1997) measured a mean altitude effect on UVI of $15.1 \% \pm 1.8 \% \mathrm{~km}^{-1}$ in the Alps; Schmucki and Philipona (2001) estimated, from more than $3 \mathrm{yr}$ of measurements in the Alps, a yearly mean noontime altitude effect of $11.0 \% \mathrm{~km}^{-1}$ with seasonal fluctuations from $8 \%$ to $16 \%$; Zaratti et al. (2003) found an altitude effect near $7 \% \mathrm{~km}^{-1}$ from UVI measurements from two low-polluted sites near La Paz, Bolivia. According to the European Cooperation in the Field of Scientific and Technical Research (COST)-713 Action, UVI increases about $6 \%-8 \% \mathrm{~km}^{-1}$ (Vanicek et al. 2000); this also agrees well with Madronich (1993), who exposed values of $5 \%-8 \% \mathrm{~km}^{-1}$ as normal altitude effects.

In this study we will split the altitude effect into two contributions-on the one hand, the effect for an aerosol-free atmosphere that is only due to the lesser molecular extinction as altitude increases; and on the other hand, the change in UVI due to the lower amount of aerosols. The method thereof is described below.

The range of $0-4 \mathrm{~km}$ is considered in this study because it covers most altitudes of human activity. All the Pyrenees Mountains are within these limits, and so this range includes all of Catalonia.

\section{4) Aerosols}

Aerosols attenuate the direct component of radiation and enhance the diffuse component. The total (diffuse + direct) irradiance is normally reduced by aerosols, except for special cases (such as with particular snowcovered surfaces) that are not considered further in this study. It has been reported that aerosols can reduce UVI by more than $30 \%$ in some polluted places (McKenzie et al. 2001b).

To explain the aerosol properties for the radiative transfer calculations the following three variables have to be known at each wavelength: AOD, SSA, and phase function, which is usually simplified through the asymmetry factor $(g)$. In practice, $g$ and SSA are considered spectrally uniform because their dependence on wavelength is supposed to be small. Reuder and Schwander (1999) reported, from Mie calculations, variations in SSA from 280 to $400 \mathrm{~nm}$ of about $+3 \%$ for both the low- and high-pollution conditions that are considered. For this, continental maritime and continental polluted aerosol types were taken respectively. For $g$, the variations were $1.2 \%$ and $2.7 \%$, respectively.

However, the works of Jacobson $(1998,1999)$ suggested that SSA might increase markedly at shorter wavelengths in the presence of organic (pollutant) aerosols. Petters et al. (2003) reported for a site in North Carolina that SSA increased from about 0.8 to 0.9 between 300 and $368 \mathrm{~nm}$. The SSA values were estimated from an inversion method combining diffuse and direct irradiance measurements at seven wavelengths together with radiative transfer modeling.

The AOD spectral dependence is often described with the coefficient $\alpha$ of Ångström's (1961) formula as follows: 
TABLE 2. Maximum absolute effects on UVI observed for SSA, $g, \alpha$, and $\mathrm{AOD}_{368}$ in the range considered. The reference values of each of these parameters considered for this analysis are also shown. In brackets there is UVI calculated for the extreme values of each parameter for $\mathrm{SZA}=0^{\circ}$ and $\mathrm{TOZ}=250 \mathrm{DU}$, which are the conditions for which the maximum absolute effects are found.

\begin{tabular}{lccc}
\hline \hline Parameter & Reference value & Range & Absolute effect on UVI \\
\hline SSA & 0.9 & $0.6-1$ & $2.8(12.3-15.1)$ \\
$g$ & 0.7 & $0.5-0.9$ & $0.8(13.9-14.7)$ \\
$\alpha$ & 1.4 & $0-2.9$ & $0.7(14.6-13.9)$ \\
AOD $_{368}$ & 0.3 & $0-1.5$ & $6.0(15.6-9.6)$ \\
\hline
\end{tabular}

$$
\operatorname{AOD}_{\lambda}=\operatorname{AOD}_{\lambda_{0}}\left(\frac{\lambda_{0}}{\lambda}\right)^{\alpha}
$$

where $\lambda_{0}$ is the reference wavelength at which AOD is set as input to the model; in this study $\lambda_{0}=368 \mathrm{~nm}$, because it is a wavelength in the UV range and out of the ozone influence.

To decide which aerosol parameters to include in the parameterization, we performed a study of $\mathrm{AOD}_{368}, \alpha$, $g$, and SSA effects on UVI with the TUV model. Also, the dependencies of this effect on SZA (from $0^{\circ}$ to $80^{\circ}$ ) and TOZ (from 250 to 450 DU) were considered. Table 2 summarizes the maximum effects on UVI found for the four aerosol parameters. These maximum effects were found at the lowest SZA and TOZ values, that is, when UVI takes maximum values. Table 2 shows the UVI values for the extreme values of each parameter. Notice that for SSA, $g$, and $\alpha$ very wide ranges were taken. For $\mathrm{AOD}_{368}$, values up to 1.5 were included, leaving out the extremely polluted cases, as pointed out above. Table 2 shows that, as expected, $\mathrm{AOD}_{368}$ is the most important parameter affecting UVI, inducing a maximum change of 6 units of UVI for the full range $\left(\mathrm{AOD}_{368}\right.$ from 0 to 1.5$)$. SSA appears to be the second more important parameter, leading to effects in UVI of 2.8 at maximum. The effects of $g$ and $\alpha$ are much smaller, up to 0.8 and 0.7 , respectively.

It was also found that, while SZA logically plays an important role in the effect of aerosols on UVI, TOZ influence is negligible, which allows separate treatment of the aerosol and ozone effects on UVI. Further details about the analyses performed and the results obtained can be found in Badosa and van Weele (2002).

These results suggested that three parameters were sufficient to explain the aerosol effect on UVI: $\mathrm{AOD}_{368}$, $\mathrm{SSA}$, and SZA. The ranges considered for $\mathrm{AOD}_{368}$ and SSA are the same as in Table 1: 0-1.5 and 0.6-1.0, respectively; $g$ and $\alpha$ are set constant at 0.7 and 1.4, respectively.

The AOD generally diminishes as altitude increases, and so it would be quite unrealistic to consider the same range of AOD at all altitudes. Moreover, this would add much complexity to the parameterization. So, a decision was made to further limit the AOD range to be accounted for by the parameterization as altitude increases; for this, the following formula representing an aerosol vertical profile was developed:

$$
\operatorname{AOD}_{368}(z)=\left[\operatorname{AOD}_{368}(0)-0.074\right] e^{-z / 1.3}+0.074 e^{-z / 8},
$$

where $\operatorname{AOD}_{368}(z)$ is the $\mathrm{AOD}_{368}$ at each altitude, and $z$ is given in kilometers.

Equation (2) has two exponential functions with two different scale factors- 1.3 and $8 \mathrm{~km}$-accounting for the variable aerosol optical depth near sea level and the assumed constant contribution outside the mixing layer, respectively. To derive these scale factors, the vertical profile of McClatchey et al. (1972) for $23 \mathrm{~km}$ of visibility normalized to the sea level value was fitted. The multiplying factors of the exponential functions were found by requiring that at $6 \mathrm{~km}$ above sea level, the overhead AOD at $550 \mathrm{~nm}$ is 0.02 when AOD at sea level is around 0.1. This is consistent with the specifications of the Radiation Commission of IAMAP (1986) for the continental II aerosol profile plus the background contribution. It is also consistent with d'Almeida et al.'s (1991) recommendations for clean continental aerosols.

Strictly, Eq. (2) has physical meaning only when $\mathrm{AOD}_{368}(0)>0.074$. However, this limitation does not cause practical problems because this AOD value is very small. Further, when using Eq. (2) to produce AOD profiles, we recommend setting $\operatorname{AOD}_{368}(0)=$ 0.074 if a lower value had to be considered.

Applying Eq. (2), the maximum value of $\mathrm{AOD}_{368}$ considered for the parameterization is 1.5 for $z=0 \mathrm{~km}$, 0.73 for $z=1 \mathrm{~km}, 0.36$ for $z=2 \mathrm{~km}, 0.19$ for $z=3 \mathrm{~km}$, and 0.11 for $z=4 \mathrm{~km}$. Of course this is a simplification of reality and it has to be understood as such.

\section{c. Mathematical expression}

PTUV consists of three basic multiplying factors: the main factor $\left(\mathrm{UVI}_{0}\right)$, which gives UVI at sea level as a function of SZA and TOZ for aerosol-free conditions; a factor considering the altitude effect for a clean atmosphere $\left(f_{z}\right)$; and a term to account for the aerosol effect $\left(f_{\text {aer }}\right)$, also considering a reduction of aerosols with altitude. The equation that expresses the fitted UVI is then

$$
\mathrm{UVI}_{f}=\mathrm{UVI}_{0} f_{\mathrm{aer}} f_{z} \text {. }
$$

$\mathrm{UVI}_{0}$ was found using the same fitting formula as Allaart et al. (2004),

$$
\begin{aligned}
\mathrm{UVI}_{0}= & {\left[E_{0} S \mu_{x} \exp \left(-\frac{\tau}{\mu_{x}}\right)\right] } \\
& \times\left[F X^{G}+\frac{H}{\mathrm{TOZ}}+J\right],
\end{aligned}
$$


where

$$
\begin{aligned}
\mu_{x} & =\mu_{0}(1-\varepsilon)+\varepsilon, \quad \mu_{0}=\cos (\mathrm{SZA}), \\
X & =(1000 \mathrm{DU}) \times \mu_{0} / \mathrm{TOZ},
\end{aligned}
$$

and $E_{0}$ accounts for the sun-earth distance seasonal variation, which affects UVI by $\pm 3.5 \%$ at maximum (e.g., Iqbal 1983).

The values of the coefficients in Eq. (4) were found by fitting the UVI that was calculated from TUV for SZA and TOZ ranging from $0^{\circ}$ to $80^{\circ}$ (with eight steps) and 200-500 DU (with six steps), respectively (see Table 1). The altitude was set at sea level and no aerosols were considered. The values found for the coefficients were $\varepsilon=0.14, S=1.22, \tau=0.48, F=3.17, G=$ $1.32, H=-126 \mathrm{DU}$, and $J=1.43$.

The fitting was achieved by using the LevenbergMarquardt nonlinear fitting method (under Microcal Origin 6.0 software), and using a weighting factor proportional to UVI in order to reduce the absolute errors. The coefficient values found here differ from those of Allaart et al. (2004) because of the different dataset used, the inclusion of aerosol contribution, and differences in the fitting methods.

To explain the relative effect of aerosols on UVI, consider the following exponential function:

$$
\begin{aligned}
\frac{\mathrm{UVI}\left(\mathrm{SZA}, \mathrm{TOZ}, \mathrm{AOD}_{368}, \mathrm{SSA}\right)}{\mathrm{UVI}\left(\mathrm{SZA}, \mathrm{TOZ}, \mathrm{AOD}_{368}=0\right)} & \cong \text { faer } \\
& =e^{- \text {(SZA,SSA)AOD } 368} .
\end{aligned}
$$

In Eq. (5), $b$ is a function of SZA and SSA that can be expressed in two separate polynomial terms,

$$
\begin{aligned}
b(\mathrm{SZA}, \mathrm{SSA})= & \left(0.344+0.773 \mu_{0}-1.368 \mu_{0}^{2}\right. \\
& \left.+0.580 \mu_{0}^{3}\right)[1-5.33(\mathrm{SSA}-0.9) \\
& \left.-2.77(\mathrm{SSA}-0.9)^{2}\right] .
\end{aligned}
$$

Coefficients in Eq. (6) have been found by fitting TUV calculations for sea level altitude, and for the same SZA and TOZ conditions as for Eq. (4), together with $\mathrm{AOD}_{368}$ ranging from 0 to 1.5 (with seven steps) and SSA from 0.6 to 1 (five steps, see Table 1) using the Levenberg-Marquardt nonlinear fitting method.

As seen above, a wide range of ratios have been reported from different studies to explain the altitude effect. Here, this effect has been divided in two partsone accounting for the reduction of aerosol optical depth as altitude increases, and the other explaining the enhancement that is produced as the atmosphere becomes thinner when altitude increases. The first contribution is taken into account in Eq. (5) by introducing the actual $\mathrm{AOD}_{368}$ value estimated or measured at the

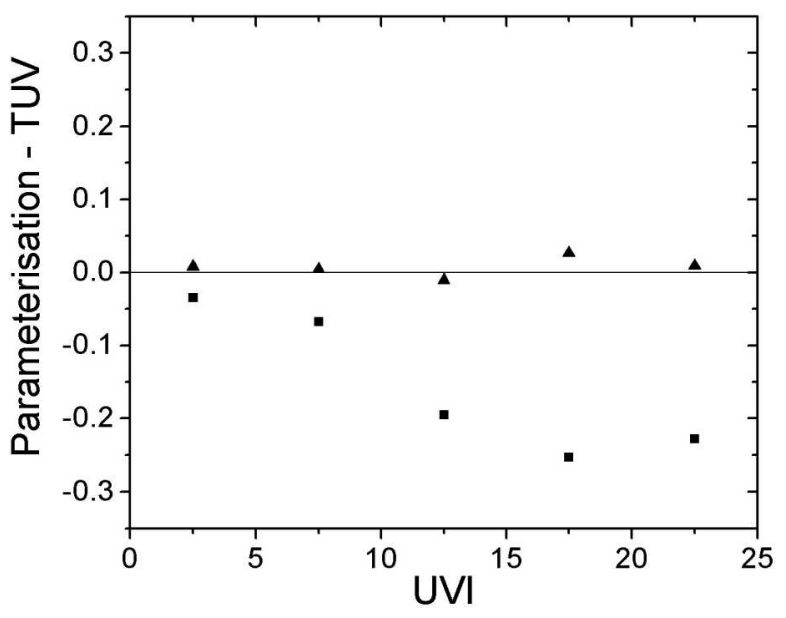

FIG. 2. Mean errors committed by the parameterization through bins of TUV UVI before (squares) and after (triangles) the application of Eq. (8).

considered altitude. This value should lie within the limits marked by Eq. (2) for which the parameterization is valid. The $\mathrm{AOD}_{368}$ in Eq. (5) can be estimated through Eq. (2), if required. For the second contribution, an increment of $5 \% \mathrm{~km}^{-1}$ is assumed, which represents what is found in average with TUV model calculations (see discussion above). This ratio was also used for ALUVI to describe the altitude effect. The altitude factor is then

$$
f_{z}=1+0.05 z .
$$

The comparison of the results given by Eqs. (4) and (5) with TUV calculations separately showed maximum absolute errors of \pm 0.2 in UVI. Because these two equations had been retrieved for sea level conditions, the next step was to combine them with Eq. (7), and finally compare the results from Eq. (3) with TUV UVI calculations that considered the altitude change. The UVI calculations were done for the all of the 15 120 conditions listed in Table 1. The considered $\mathrm{AOD}_{368}$ value changed with altitude according to Eq. (2). Figure 2 shows the mean differences between the parameterization and the TUV model through bins of UVI (square points). The parameterization deviated from the model systematically down to -0.3 in UVI. So, in order to improve the agreement, the following correction was applied to $\mathrm{UVI}_{f}$, giving the final expression of PTUV:

$$
\begin{aligned}
\text { PTUV }= & 0.0713+0.9471 \mathrm{UVI}_{f}+0.005213 \mathrm{UVI}_{f}^{2} \\
& -\left(1.565 \times 10^{-4}\right) \mathrm{UVI}_{f}^{3} .
\end{aligned}
$$

After this correction the mean differences remain very close to 0 for the whole UVI range, as shown in Fig. 2 (triangle points).

In comparison with TUV with eight streams, PTUV performs calculations with a speed about 2000 times as 

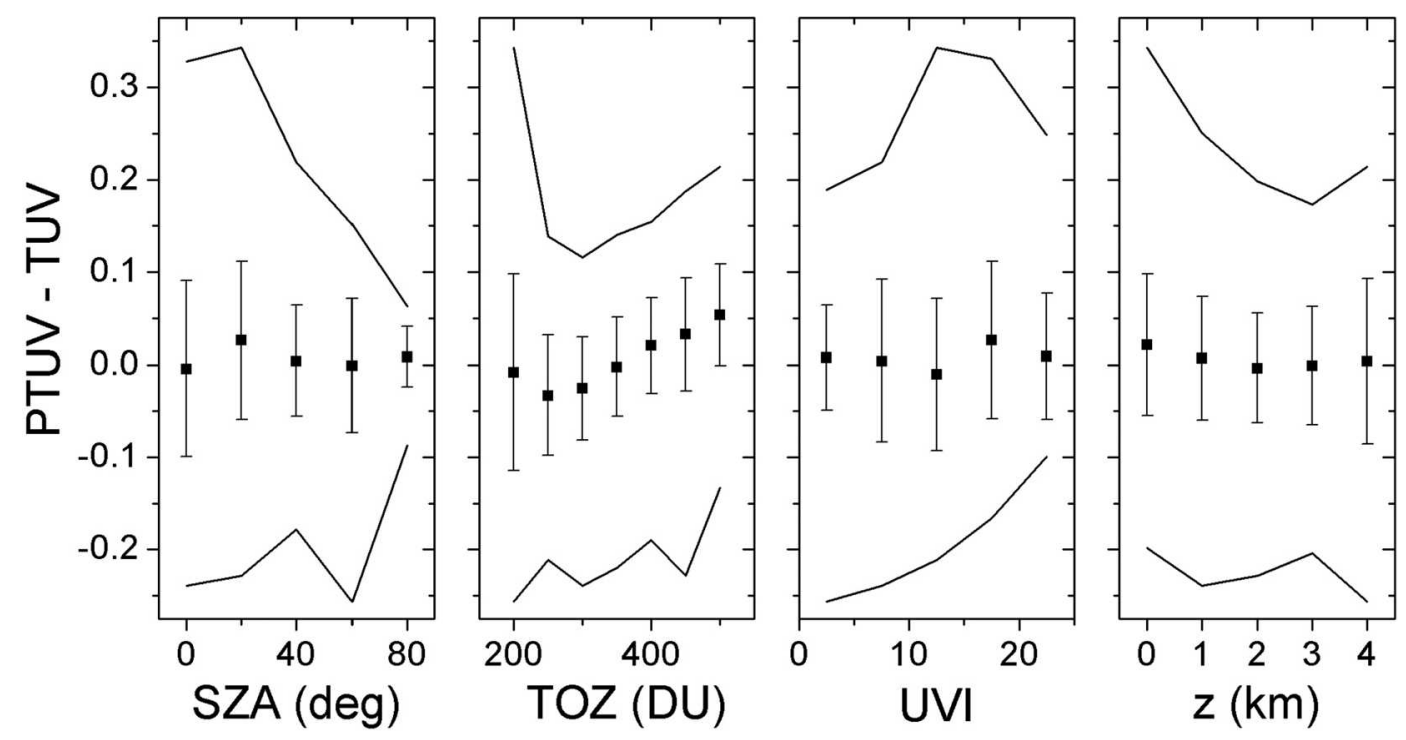

FIG. 3. Mean absolute errors as function of SZA, TOZ, $z$, and TUV UVI. Standard deviation is shown through the vertical error bars, and maximum absolute errors are represented in lines.

fast. In comparison with the two-streams code, the PTUV is about 50 times as fast.

\section{d. Model versus parameterization}

To estimate the errors arising from approximating TUV results by a parameterization such as PTUV, values from the same 15120 cases in Table 1 have been carefully compared. As a result of the comparison, absolute errors are found to range from -0.26 to 0.34 , although $88 \%$ of the cases are within \pm 0.1 , and $99 \%$ are within \pm 0.2 in UVI. Useful information about the maximum absolute errors can be found in their representation as functions of different parameters. Figure 3 shows the distribution of averaged absolute errors through bins of SZA, TOZ, $z$, and UVI. Error bars representing the standard deviation and two curves accounting for the maximum errors are also shown. As expected, the maximum absolute errors take place for low SZA; however, the largest of these errors are found for very low values of TOZ, around $200 \mathrm{DU}$, which are, in general, rare conditions. The largest discrepancies between the model and the parameterization occur for low-altitude sites, where a large fraction of aerosol load is present. Also the largest absolute errors are found for very low values of SSA. In the case of $\mathrm{AOD}_{368}$ (not shown), no significant tendency has been detected. Thus, maximum absolute errors of the parameterization are found when combining very low values of SZA, TOZ, and SSA, which are extreme cases, together with low altitude.

Concerning relative errors, in $95 \%$ of the cases with UVI larger than 2 the errors are within $\pm 3 \%$. For lower values of UVI (and, thus, larger SZA, i.e., lower solar altitudes) the relative errors take much larger values. This is due to the model-fitting criterion of giving more importance to the points with larger UVI values. The points with largest relative differences are also associated with noncommon conditions and with very low absolute errors, which are within \pm 0.19 for UVI $<2$.

\section{Validation test}

\section{a. Comparison with UVI from high-quality spectral measurements}

For this study we took $1 \mathrm{yr}$ (2001) of high-quality spectral irradiance measurements from an instrument manufactured in house at NIWA (McKenzie et al. 1992). It was sited in Lauder, New Zealand $\left[45.04^{\circ} \mathrm{S}\right.$, $169.684^{\circ} \mathrm{E}, 370 \mathrm{~m}$ above mean sea level (MSL)]. The measurements are taken at the Southern Hemisphere midlatitude site for the Network for the Detection of Stratospheric Change (NDSC), and the UV data comply with NDSC quality standards (McKenzie et al. 1997). Spectra are taken at $5^{\circ}$ of SZA (for $\mathrm{SZA}<95^{\circ}$ ), except that during $2 \mathrm{~h}$ around noontime the frequency is $15 \mathrm{~min}$. The spectra are processed and weighted by the CIE function to obtain the UV index value. For the PTUV modeling, TOZ was taken from assimilated measurements from TOMS and $\mathrm{AOD}_{368}$ was taken from $\mathrm{AOD}_{412}$ retrievals from multifilter measurements converted to $368 \mathrm{~nm}$, considering an alpha of 1.4. The SSA was set constant to 0.9 , which is the middle value of the range that is considered as being typical (0.80.999) in the UV range (Madronich 1993; Petters et al. 2003). In any case, when not considering high-polluted 

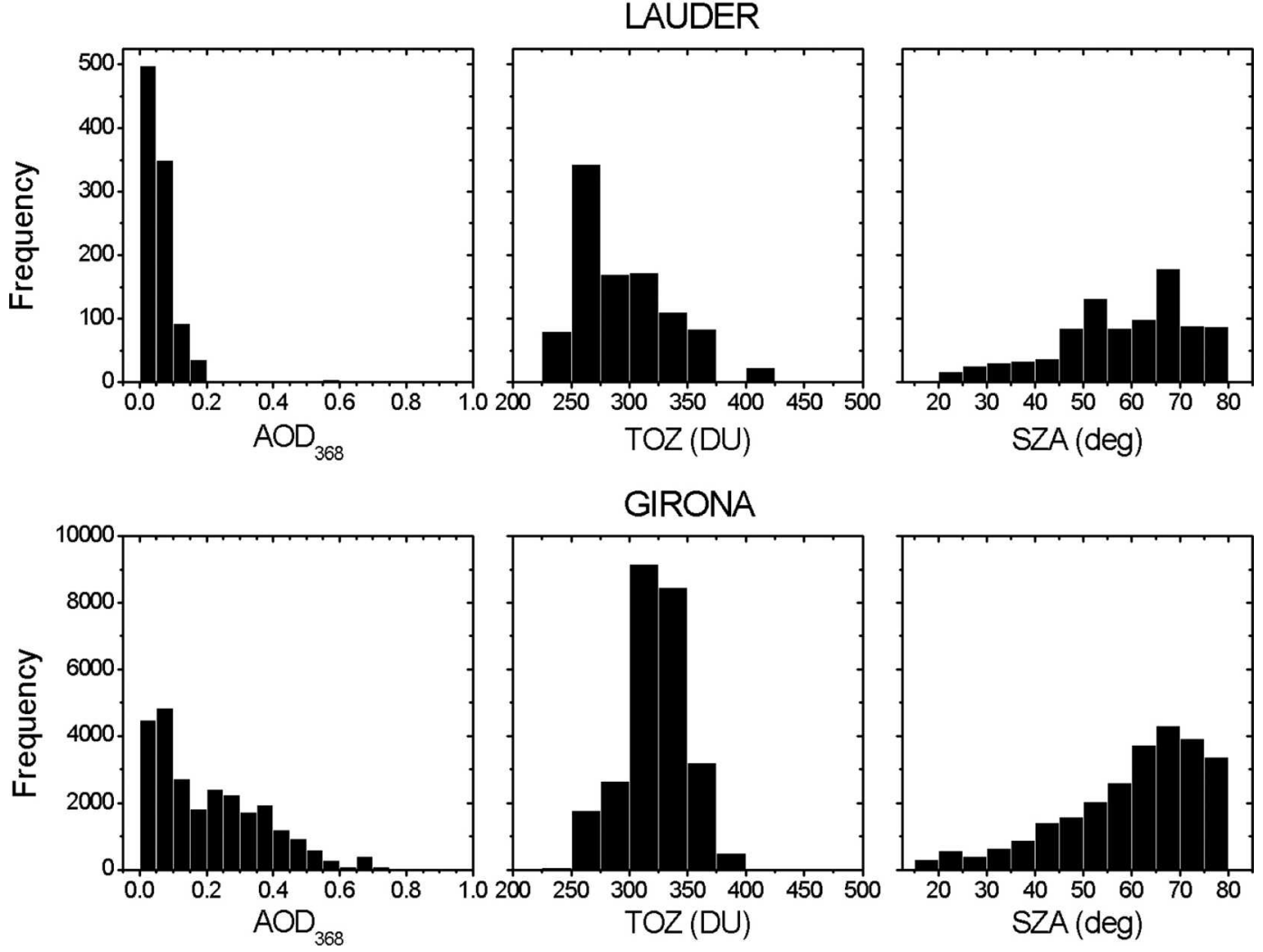

FIG. 4. $\mathrm{AOD}_{368}$, TOZ, and SZA histograms for the datasets in Lauder and Girona.

sites, the effect of slight differences in SSA values is low (Petters et al. 2003).

Only entirely clear days were selected for the comparison, although we were forced to remove some half days because of the lack of AOD measurements. In this way, $11 \%$ of the initial dataset was finally considered, which is a total of 979 records, with 11 summer days, 21 autumn days, 18 winter days, and 7 spring days.

Figure 4 presents histograms for SZA, TOZ, and $\mathrm{AOD}_{368}$ for this dataset in order to show the ranges and the frequency of values for this comparison. In Lauder the pollution is very low, with $\mathrm{AOD}_{368}$ usually below 0.2 ; although, for the dataset considered here, 1 day with an $\mathrm{AOD}_{368}$ of almost 0.6 is found, which is most likely due to the influence of a fire. The climatological mean $\mathrm{AOD}_{368}$ at Lauder is $\sim 0.05$, making it an exceptionally clean site by global standards (Liley and McKenzie 2002). A wide range for TOZ (229-400 DU) is found, but with $80 \%$ of the cases under $325 \mathrm{DU}$; values from $21^{\circ}$ to $80^{\circ}$ of SZA are reported with more frequency for large angles.

Figure 5 shows the plotted PTUV versus the measured UVI. The points appear to be well aligned, giving a regression coefficient of the linear fit of 0.9989 . From the slope " $\mathrm{B}$ " of the fit it is seen that PTUV systemati- cally overestimates UVI by about $4 \%$. This bias is a reasonable order of magnitude when the uncertainties are taken into account. The best current UVI measurements have a $5 \%$ of uncertainty (Bais et al. 2001); also, the TOZ retrievals have uncertainties that are about this order of magnitude (Bodeker et al. 2001). Of course, PTUV has an intrinsic source of error both because the TUV model (which is based to) itself has uncertainties and because the parameterization is a simplification of this numerical model. However, this latter aspect should not significantly contribute to the systematic bias that is observed in Fig. 5, only to the dispersion of the points because it has been shown above that PTUV and TUV have almost no systematic deviations. The selection of cloudless days was based on the visual inspection of the data, so this could have introduced more uncertainty in the comparison thereby also affecting the dispersion of the points. Because there is a low aerosol load in Lauder the uncertainties in the aerosol information cannot affect the comparison significantly.

We also investigated whether there was any sensitivity to the range of TOZ and SZA included in the analysis. We found that any differences were within the range of experimental uncertainty. 


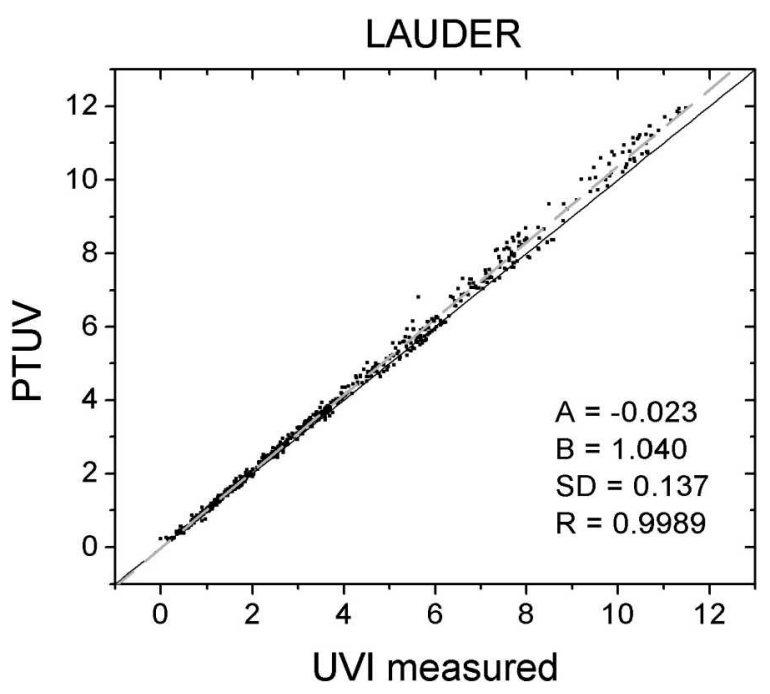

FIG. 5. PTUV vs UVI measured in Lauder. The dashed line represents the result of the linear fit; the values of the parameters $A, B$, and $R$ for the fit are shown together with the SD as an estimation of the dispersion of the points. The solid line symbolizes the perfect model-measurement agreement.

\section{b. Comparison with UVI from a Robertson- Berger-type meter}

Here the attention will be focused on testing the performance of PTUV for contrasted AOD scenarios.

For this, the dataset that is used is a 15 -month period (December 2001-February 2003) of 1-min-resolution UVI measurements with a Kipp \& Zonen UV-S-E-T broadband erythemal radiometer in Girona $\left(41.97^{\circ} \mathrm{N}\right.$, $\left.2.82^{\circ} \mathrm{E}, 100 \mathrm{~m} \mathrm{MSL}\right)$, Spain.

These measurements from Girona were calibrated against the TUV model so no systematic deviations in the model-measurement comparison were expected. This makes it easier to study how different ways of introducing the aerosol information affects the model-versusmeasurement comparison through the change in the dispersion of the residues (i.e., model minus measurement).

Different calibration factors were found as a function of SZA and TOZ to also correct for the nonideal spectral response of the sensor. As is well known, the spectral response of broadband erythemal UV radiometers is just an approximation to the CIE spectral response. If not corrected, the deviation from this ideal response can lead to maximum errors of about $20 \%-80 \%$ in measured UVI, depending on the instrument (e.g., Leszczynski et al. 1998). Thus, to accurately calibrate this type of instrument it is not sufficient to use a constant absolute calibration factor. The correct calibration factor also depends on SZA and TOZ because these are the main variables influencing the spectral shape of solar radiation in the UV band.

A calibration factor value was found for each of the $5^{\circ}$ of SZA (from $0^{\circ}$ to $80^{\circ}$ ) and $10 \mathrm{DU}$ of $\mathrm{TOZ}$ (from 200 to 500 DU) by calculating the ratio between UVI with the CIE spectral response and UVI with the spectral response of the sensor (given by the manufacturer). This gave a lookup table from which the calibration factor for each condition was deduced through linear interpolation. Daily TOZ values were taken from TOMS.

Strictly, with the measurements, the angular response of the instrument, which deviates from the cosine response, should be corrected. However, here this correction is not applied for the UV-S-E-T instrument, because its angular response is seen to be very good-less than $\pm 4 \%$ from $0^{\circ}$ to $70^{\circ}$ of SZA, according to the manufacturer. Leszczynski et al. (1998) showed that such a deviation induces an angular correction in UVI that is much lower than this $\pm 4 \%$, which makes it reasonable to neglect this correction.

Cloudless records were selected through visual inspection of both total global and diffuse concurrent measurements. This selection reduced the dataset to $11 \%$ of its original size. The final dataset contains 25 766 records and involves 104 days-34 in winter, 34 in spring, 22 in summer, and 14 in autumn. Because nonsmooth variations are usually observed in UVI around noontime, mostly in the hotter months, records between 1100 and 1300 TST could be selected only in 18 days, almost all of which are from winter and spring.

For the modeling, assimilated retrievals of TOZ from TOMS were used as input. Again, SSA was kept constant at 0.9. Concerning $\mathrm{AOD}_{368}$, no specific measurements of AOD are available in Girona. However, concurrent measurements of total global irradiance and diffuse irradiance were available from CM11 pyranometers, and from shaded Kipp \& Zonen pyranometers, respectively, and so estimations of Ångström's $\beta$ (i.e., AOD at $1000 \mathrm{~nm}$ ) were possible. The simple algorithm suggested by Gueymard and Vignola (1998) was used,

$$
K=0.04+1.45 \beta,
$$

where $K$ is the ratio between the diffuse and direct normal irradiances. An alpha of 1.4 was used to convert AOD at the UV wavelengths. Gueymard and Vignola (1998) recommend that Eq. (9) be used for SZA $<75^{\circ}$ and $\beta<0.35$. However, here SZA conditions up to $80^{\circ}$ are considered.

The $\mathrm{AOD}_{368}$, TOZ, and SZA histograms for Girona are presented in Fig. 4. In Girona, there is much more turbidity than in Lauder, which is shown through the wide range of $\mathrm{AOD}_{368}$ found up to 1. Regarding TOZ, values from 246 to $486 \mathrm{DU}$ are found, although most of the records remained around $325 \mathrm{DU}$, mainly because of the greater presence of winter and spring days.

Figure 6 shows the results of the model-measure- 

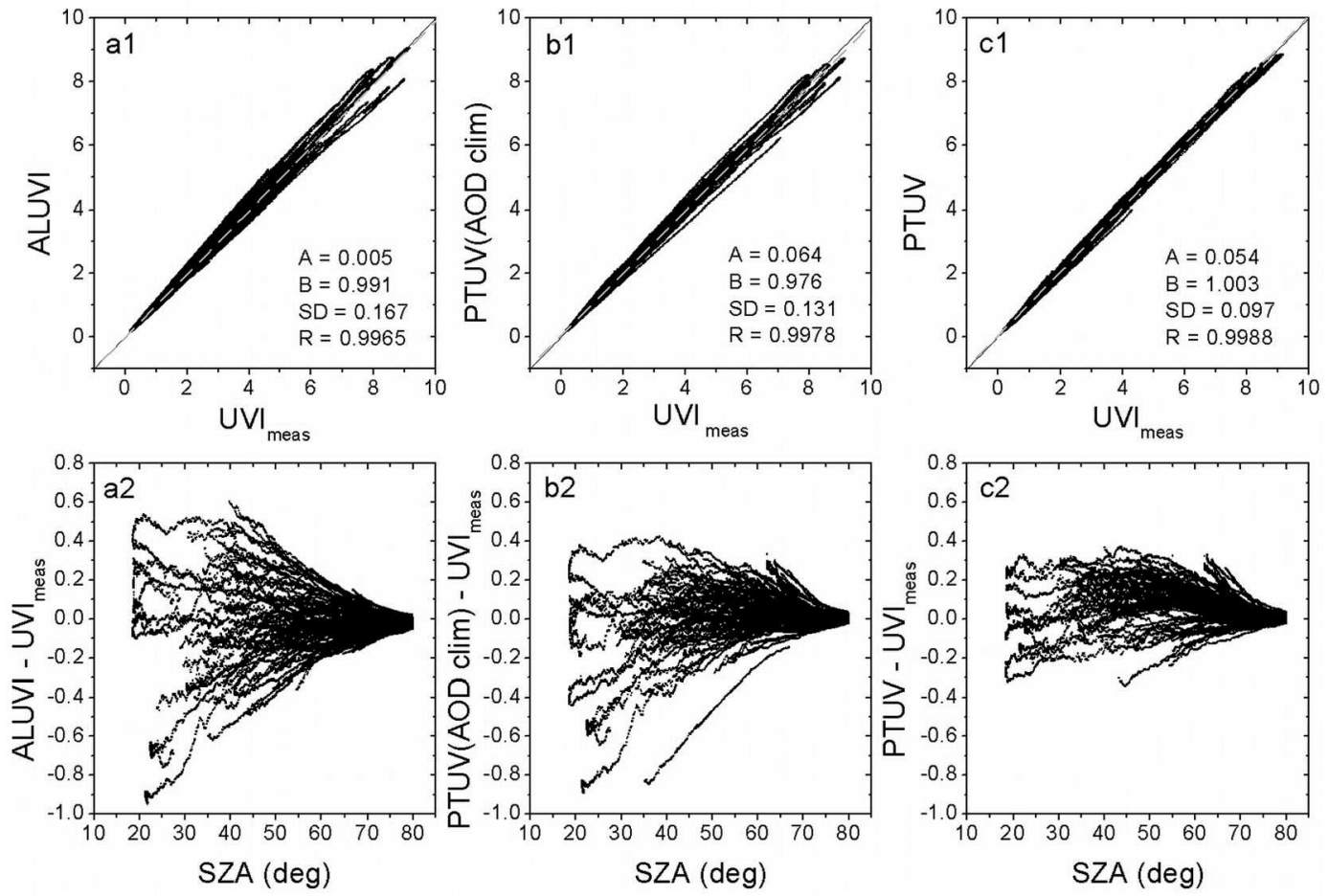

FIG. 6. 1) UVI modeled-vs-measured and 2) the residues vs SZA plots for with the dataset from Girona and three different ways of modeling-(a) ALUVI; (b) PTUV with AOD climatic from González et al. (2001); (c) PTUV with the actual AOD conditions from Eq. (9). Dashed lines and solid lines are represented in model-vsmeasurement plots accounting for the linear fit and perfect agreement lines, respectively. The linear fit statistical parameters $A, B, \mathrm{SD}$, and $R$ are also shown.

ment comparison through the model-versus-measurement and residues-versus-SZA plots. Apart from the results considering PTUV with the aerosol information described above, there are two additional comparisons using different types of modeling that consider two other ways of taking into account (implicitly and explicitly) the aerosol contribution.

On the one hand, the results with UVI calculated with ALUVI are also shown. This formula considers the SZA, TOZ, $E_{0}$, and a $5 \% \mathrm{~km}^{-1}$ altitude effect as input information and is a result of fitting UVI from Brewer spectrophotometer measurements taken in De Bilt (Netherlands) and Paramaribo (Surinam). Thus, ALUVI has implicit aerosol information. On the other hand, PTUV is used with climatic information of $\mathrm{AOD}_{368}$ as input. Monthly typical values of Ångström's $\beta$ in Girona are considered from González et al. (2001) based on an algorithm that is more rigorous (Gueymard 1998) than the one in Eq. (9) that was applied to 4 yr of broadband total and diffuse measurements. Despite the limited period, these typical values will be considered as climatic hereinafter. An alpha value of 1.4 is used then to convert AOD to $368 \mathrm{~nm}$. This annual variation of $\mathrm{AOD}_{368}$ is shown in Fig. 7.
As shown in Fig. 6, for the three cases the modelversus-measurement plots (Figs. 6a1, 6b1, 6c1) show excellent correlations, with $R$ always larger than 0.996 . For Fig. 6a1, which corresponds to the comparison using ALUVI, a good slope is found, with $B=0.991$. In Fig. 6b1, for which PTUV with climatic AOD is used, a lower slope is found, with $B=0.976$.

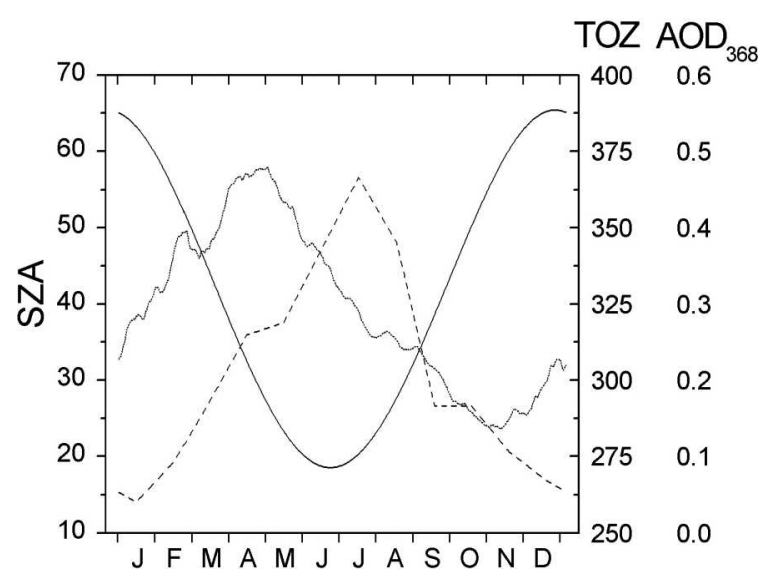

FIG. 7. Annual variation of SZA (solid line) in degrees, TOZ (dotted line) in DU, and $\mathrm{AOD}_{368}$ (dashed line) for Girona. 
The linear fit for Fig. $6 \mathrm{c} 1$ gives $B$ very close to $1(B=$ $1.003)$, which is logical, given the way the measurements were calibrated. Notice that PTUV tends to underestimate the UVI measurements by about $2.2 \%$ because of the different aerosol information that is considered. The most remarkable aspect is the clear differences that are observed in the dispersion of the points, which are mathematically expressed through the standard deviation (SD). The largest dispersion is found for ALUVI (SD = 0.167) because of its implicit and placebased treatment of aerosols. When climatic values for AOD are introduced to PTUV, a lower SD value is found ( $\mathrm{SD}=0.131)$. The lowest dispersion is found when more aerosol information is considered in the model, that is, in the Fig. $6 c 1$, where $\mathrm{SD}=0.097$. This implies a reduction in SD of $27 \%$ with regard to the SD for PTUV with climatic AOD.

These differences in the dispersion are also clearly evident in the residues-versus-SZA plots (Figs. 6a2, $6 \mathrm{~b} 2,6 \mathrm{c} 2)$. For the comparison with ALUVI, the following widest range of residues is found: $-0.95+0.60$ in UVI. In Fig. 6b2, from the comparison using PTUV with climatic AOD, a slightly narrower range is found of $-0.90+0.42$ in UVI. The residues for PTUV with concurrent $\mathrm{AOD}_{368}$ from Eq. (9) (Fig. 6c2) take values within a limited range in UVI of \pm 0.37 . Thus, a clear relation appears between $\mathrm{SD}$ and the residues range; so the larger the SD the larger the residue range.

These analyses show that the PTUV model is able to explain different (but not extreme) AOD situations, giving a good model-measurement agreement. Moreover, from Fig. 6 it is apparent that considering concurrent information for AOD into the model gives much better results than taking into account climatic values or implicit contributions. Slightly better results in the dispersion of the points are found when climatic aerosol information from the working site is explicitly introduced to PTUV, as compared with ALUVI, which implicitly considers aerosol information from a different site. In spite of this, a better model-versus-measurement agreement (i.e., a value of $B$ closer to 1 ) is found for ALUVI than for PTUV with climatic AOD.

The reason why PTUV with climatic AOD and ALUVI give similar results for Girona is because the aerosol characteristics for this site are similar to those in the measurements that are used to retrieve ALUVI. The latter algorithm, when applied to the dataset from Lauder (section 3a), gives UVI values that are $6 \%$ lower than PTUV (with both climatic AOD estimations and the AOD actual measurements that are available), because the aerosol contribution that is implicitly accounted for by ALUVI is overestimated.

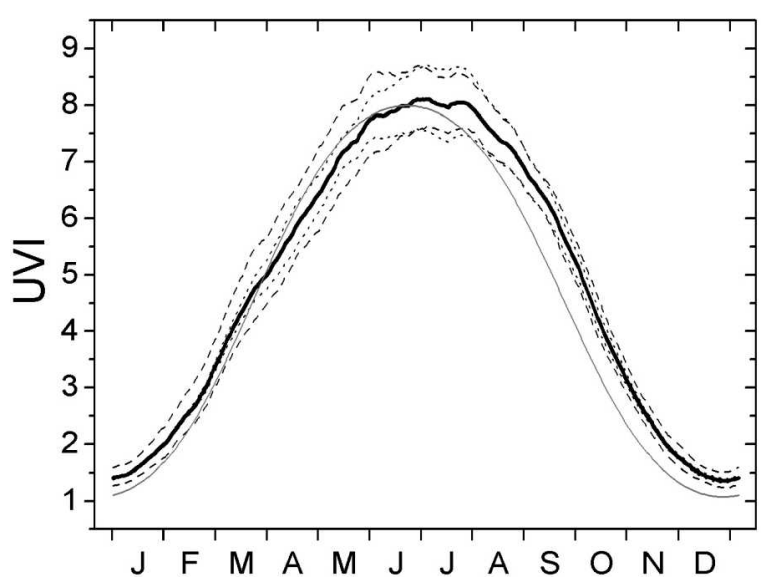

FIG. 8. Annual variations in UVI (for Girona) calculated with PTUV using the values in Fig. 7 (solid thick line), with TOZ plus or minus one standard deviation (dashed lines), with $\mathrm{AOD}_{368}$ plus or minus one standard deviation (dotted lines), and with TOZ and $\mathrm{AOD}_{368}$ set constant to $337 \mathrm{DU}$ and 0.39 , respectively (solid gray line).

\section{Seasonal UVI maps}

\section{a. Climatic annual variation of UVI}

To know the typical UVI values for Catalonia it is interesting to see the seasonal variation of some of the variables that affect UVI most, that is, SZA, TOZ, and AOD. For this analysis, Girona has been chosen because for this site there are some data that are available about typical turbidity on a monthly basis (González et al. 2001), as discussed above. TOZ is calculated through moving averages of \pm 5 days from 25 yr (1979-2003) of Earth Probe TOMS assimilated measurements. Because these measurements have a latitude $\times$ longitude resolution of $1^{\circ} \times 1.25^{\circ}$, Catalonia is completely covered with seven cells (see Fig. 1). Girona is very close to the border between cell 3 and 6 , and so the TOZ for this site has been calculated as the mean value of these two cells.

Figure 7 shows the annual change of noontime SZA, TOZ, and $\mathrm{AOD}_{368}$. Maximum TOZ values are detected in April, and minimum values are at the end of October and beginning of November; the range is 284-370 DU. Monthly climatic values of $\mathrm{AOD}_{368}$ range from 0.04 (in January) to 0.47 (in July). The shape of the curve shows that there are more aerosols during spring than in autumn. The range of noontime SZA for the considered dataset is from $18.5^{\circ}$ to $65.4^{\circ}$.

Note that the maximum and minimum values take place in different months, depending on the variable. Consequently, although SZA is the dominant factor used to describe the annual UVI variation, it is also considerably affected by the shifted variations of $\mathrm{AOD}_{368}$ and, most of all, TOZ. Figure 8 shows the resulting UVI annual curve that is calculated with PTUV, considering these variations of SZA, TOZ, and 
$\mathrm{AOD}_{368}$ (thick line). The UVI curve that is calculated with the summer solstice mean TOZ (337 DU) and $\mathrm{AOD}_{368}(0.39)$ values (solid gray line) is also plotted. Differences in the shapes of the curves are clear. The "realistic" line is asymmetric with respect to the summer solstice, with UVI values that are about 1 unit larger at the autumn equinox than at the spring equinox and some oscillations, which are mainly caused by the TOZ annual and day-to-day variations. Moreover, the maximum UVI of the curve, which is around 8, is detected during all of June and July and not only around the summer solstice, which is an important aspect to take into account for UV damage prevention purposes. This fact is produced by the reduction in TOZ in summer that partly compensates for the effect of the increase of the noontime SZA.

Figure 8 also shows the UVI curves for TOZ and $\mathrm{AOD}_{368}$ from Fig. 7 plus and minus one standard deviation. The std devs of TOZ are around 34-44 DU in winter, 19-41 DU in spring, 12-20 DU in summer, and 16-31 DU in autumn. This leads to much larger dayto-day variability of UVI in the first two seasons than for the latter two, which is clearly seen in Fig. 8 (dashed curves). Concerning $\mathrm{AOD}_{368}$, the std dev is around 0.17 in summer and is much lower, around 0.05 , in winter. This aerosol variability induces variability in UVI (dotted curves) that is comparable with the TOZ-induced variability near summer but is much lower for the rest of the year. This gives more evidence that it is important to know the aerosol (or turbidity) properties to characterize UVI accurately, particularly in summer.

While the annual UVI considering the climatological mean values of $\mathrm{TOZ}$ and $\mathrm{AOD}_{368}$ reaches a maximum of 8 units, when introducing TOZ and $\mathrm{AOD}_{368}$ minus their std devs into PTUV, a June-July UVI of 9.3 is reached (the corresponding curve is not shown here), which is $16 \%$ larger.

All of these considerations show the complexity of UVI values that are expected. For the construction of typical UVI maps in Catalonia, climatological mean values of TOZ and $\mathrm{AOD}_{368}$ will be used, but the comments above have to be taken into account.

\section{b. Construction of seasonal UVI maps}

Four maps are presented, corresponding to the solstices and equinoxes at noon, in order to see the seasonal differences (see Fig. 9). A resolution of $1 \mathrm{~km} \times 1$ $\mathrm{km}$ is taken, which involves $268 \times 278$ nodes.

The values of TOZ have been found also from moving averages of \pm 5 days of $25 \mathrm{yr}$ and averaging together the seven values that TOMS gives for all of the region of Catalonia each day (see Fig. 1). In this way, for each day one value of TOZ is taken to represent all of the territory. Badosa (2002) showed that the TOZ from the seven cells of TOMS were highly correlated and showed no significant systematic differences. Consequently, it is a good approximation to assign only one TOZ value for Catalonia, although this simplification is less suitable in spring and winter when the TOZ variability is at a maximum.

Because we do not have any climatic information about aerosols for Catalonia, the monthly values of Fig. 7 have been considered to represent all of the territory. Although this situation is far from ideal, we note that this annual turbidity evolution is very similar to what other authors found from analyses for Mediterranean sites, such as Barcelona and Valencia (Lorente 1978; Pinazo et al. 1995; Pedrós et al. 1999). Equation (2) is used to extrapolate $\mathrm{AOD}_{368}$ for different altitudes.

In Fig. 9 much larger UVI values for 21 June (UVI up to 10.5 ) than for 21 December (UVI up to 2) are reported, as expected. It is also seen that UVI for 21 September and 21 March is around 6.5 and 5.5, respectively, showing about 1 point in UVI of difference, as also appeared in the above analysis for Girona.

Figure 10 shows (in gray) all of the UVI values for each map, plotted as a function of altitude. The particular case of UVI that is simulated over a range of altitudes from 0 to $3325 \mathrm{~m}$ at $42.88^{\circ} \mathrm{N}$ and $0.04^{\circ} \mathrm{E}$ (northeast corner of the maps) is shown through the black lines. Because Catalonia is a relatively small territory, the latitudinal effect is rather weak. This effect appears in Fig. 10 as the vertical dispersion of the points, which is larger for the equinoxes than for the solstices.

The altitude effect is less obvious for the nonsummer maps. Even the relative changes with altitude are smaller in winter than in summer because of the reduced aerosol loading in the boundary layer in winter (relative changes are up to $17 \%$ in winter and up to $30 \%$ in summer, as calculated from Fig. 10). For the autumn, winter, and spring maps, a maximum difference less than 1.5 in UVI is found for the whole territory. In summer the altitude effect strongly appears with differences up to 2.5 between the coast and the highest mountains. This shows, first, the need to take into account the altitude effect in Catalonia and, second, that high and harmful UV levels occur in the mountain regions.

Situations with large albedo, such as snow-covered surfaces, are not considered here. It is known that UVI in these situations is considerably enhanced. For example, Renaud et al. (2000) reported increments in UVI of $15 \%-25 \%$ due to the multiple groundatmosphere reflections under the cloudless sky and snow-covered surface conditions. McKenzie et al. (1998) showed increases of $28 \%$ for clear skies, and increases exceeding 50\% under cloudy skies. Badosa 
21 December

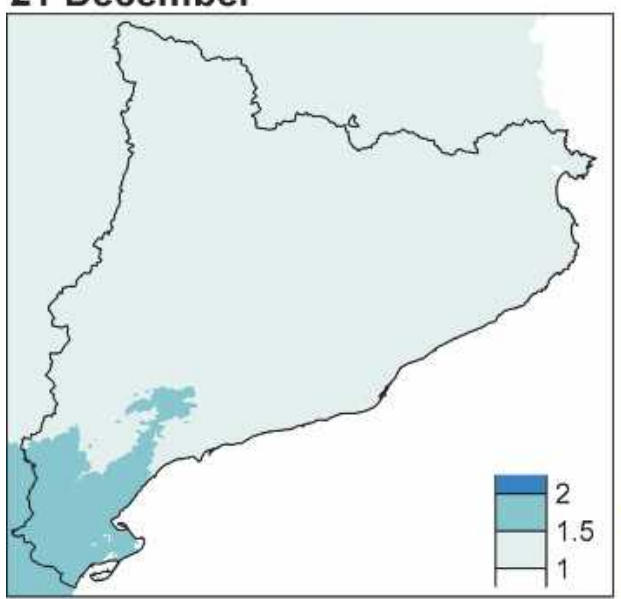

21 June

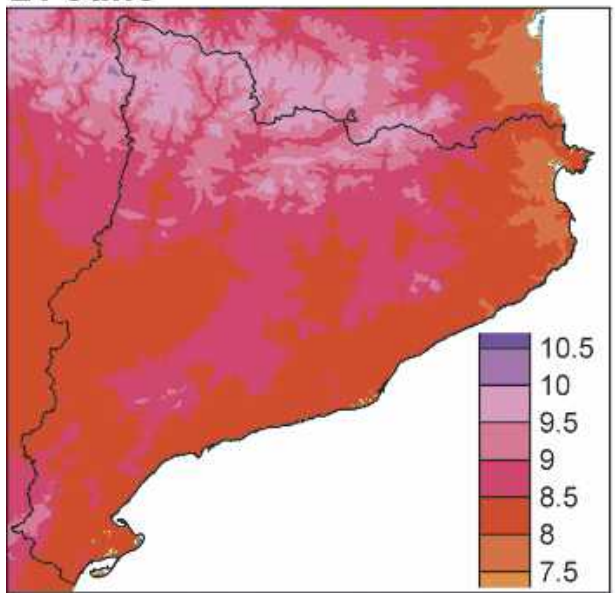

21 March

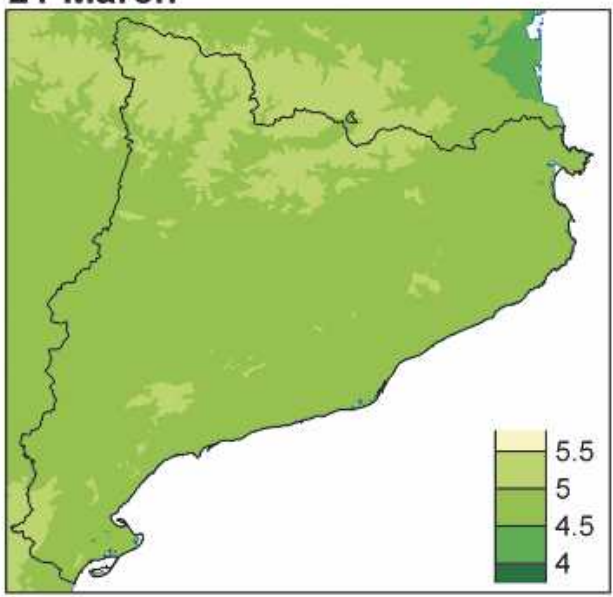

21 September

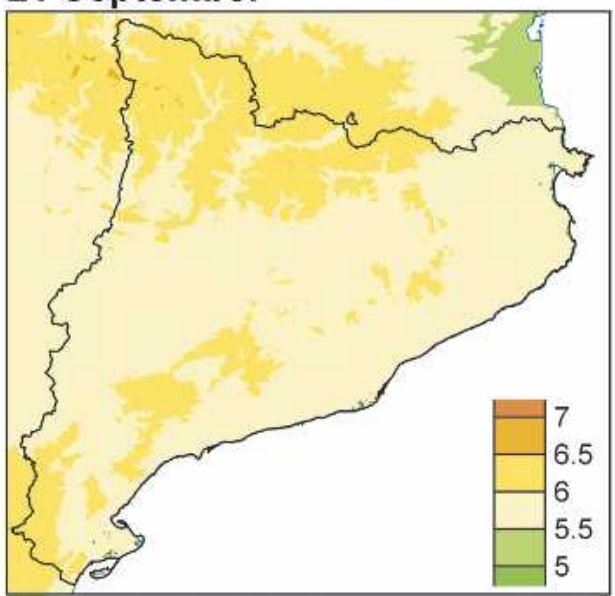

UVI

11

10.5

10

9.5

8.5

8

7.5

6.5

6.5

6
5.5

5

4.5

4
3.5

3.5

2.5

2

1.5

1.5

FIG. 9. Maps of typical UVI for cloudless and snow-free conditions in Catalonia at the solstices and equinoxes with $1 \mathrm{~km} \times 1 \mathrm{~km}$ spatial resolution.

(2002) found through modeling enhancements up to $50 \%$ due to the combined presence of aerosols and snow.

\section{Conclusions}

In this study a new, fast parameterization of the UV index, PTUV, is presented that is based on the TUV radiative transfer model. It has been applied to construct seasonal maps of the UV index for the region of Catalonia. PTUV requires limited input informationsolar zenith angle, total ozone column, and altitude, which can be easily obtained for a given site. Further, $\mathrm{AOD}_{368}$ can either be measured or estimated, and for SSA, of which the value is not well known in the UV range, a typical value as reported in the literature can be taken. Despite its simple formulation, which is very simple to program, PTUV is able to explain a wide range of cloudless situations although the current implementation excludes cases in which the turbidity or surface albedo is high.

An advantage of this parameterization is the increase in computational speed. In turn, this can facilitate, for example, the generation of daily regional forecasts of clear-sky UVI. An alternative approach would have been to calculate a multidimensional lookup table of UVI values ahead of time. The advantage of the procedure described here is that it is computationally efficient and storage requirements are greatly reduced.

From the comparison with the full radiative transfer model calculations using TUV, it is concluded that the UVI that is calculated with PTUV has maximum absolute errors from -0.26 to 0.34 , and $99 \%$ of the cases within \pm 0.2 . The maximum absolute errors are found for very low values of SZA, TOZ, and SSA, which are extreme conditions, together with low values of $z$.

From the comparison with high-quality UVI measurements from Lauder, New Zealand, it is concluded that PTUV shows a bias of about $4 \%$, which is within the absolute measurement uncertainty. From the comparison of PTUV with the UVI measurements in Girona, Spain, the ability of PTUV to explain quite differ- 


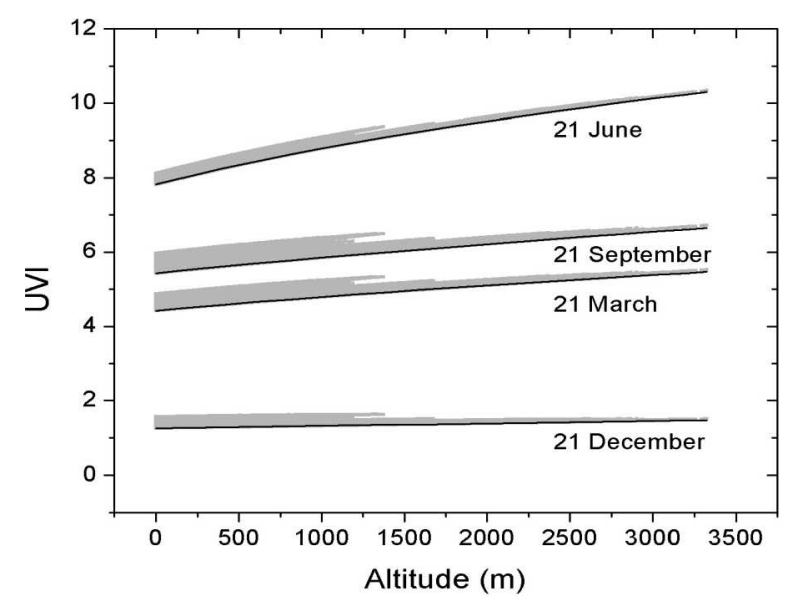

FIG. 10. UVI for the equinoxes and solstices as a function of altitude. All of the values from the maps in Fig. 9 are shown in gray; the UVI simulation from 0 to $3325 \mathrm{~m}$ at $42.88^{\circ}$ latitude and $0.04^{\circ}$ longitude is shown in black.

ent aerosol scenarios is illustrated. To estimate AOD a simple formula was used, which, despite it not being very accurate, resulted in a very useful explanation of the changes in aerosol optical depth. Absolute differences of \pm 0.37 are found when for each measurement this estimation of $\mathrm{AOD}_{368}$ is used. Considerably larger dispersions and absolute errors are found either when climatic $\mathrm{AOD}_{368}$ values are used or when the measurements are compared with an empirical formula that implicitly considers aerosols. This result underlines the importance of including aerosol variability when computing UVI.

None of the sites considered here is representative of heavily polluted conditions, which would have posed a further challenge for PTUV. Unfortunately, the availability of relevant data from heavily polluted sites is rare. In the future, when suitable data become available, we plan to test PTUV further under more polluted conditions.

Concerning the modeling of the typical UV conditions at Girona, it has been found that the combination of the different annual variations of SZA, TOZ, and AOD causes an asymmetric seasonal variation in the noontime UVI annual mean curve and leads to a long period of about 2 months (June-July) during which the UVI remains close to its maximum values. Another important result from this analysis is that at Girona in summertime the (rather low) TOZ variability and the AOD variability contribute about equally to the UVI variability. The variability in the total ozone column dominates in the other seasons.

Four seasonal noontime UVI maps for the region of Catalonia have been presented. UVI values on the winter solstice map are about 1/6 those on the summer solstice map. The spring equinox map has UVI values that are around 1 point below the autumn equinox map because of the difference in TOZ. The range of UVI over the whole territory is typically less than 1.5 , except in the summer when differences up to 2.5 in UVI are found between the coast and the highest mountains. If snow presence had been considered, more variation would have been found in wintertime because of the higher UVI values at the mountainous areas.

The use of PTUV for UVI forecasting will be tested in future work. For this, the current form of the parameterization can be applied directly to make assumptions about the next day's total ozone column (TOZ), aerosol load (AOD), and properties (SSA). Also, an extension of PTUV to include the surface albedo effect should be investigated.

Acknowledgments. This work has been partly funded by the projects IMMPACTE from the Ministry of Environment of the Government of Catalonia and DEPRUVISE (REN2000-0903-C08-01/CLI) from the Ministry of Science and Technology of the Government of Spain.

This work was undertaken by the lead author as part of a predoctoral scholarship from the Ministry of Universities, Research and Information Society of the Government of Catalonia. It follows on from collaboration at KNMI under the supervision of Michiel van Weele. We acknowledge the contribution to this work arising from the algorithms described by Allaart et al. (2004).

We also thank Alexander Los from Kipp \& Zonen for his kind dedication and efforts in the characterization of the sensor in Girona.

\section{REFERENCES}

Allaart, M., M. van Weele, P. Fortuin, and H. Kelder, 2004: An empirical model to predict the UV-index based on the solar zenith angles and total ozone. Meteor. Appl., 11, 59-65.

Ångström, A., 1961: Techniques of determining the turbidity of the atmosphere. Tellus, 13, 214-223.

Badosa, J., 2002: Mesures d'irradiancia eritematica a Catalunya vs. modelitzacions per cels serens a partir de la columna d'ozo d'EP/TOMS (Erythemal irradiance measurements in Catalonia vs. modelling for clear skies using the ozone column from EP/TOMS). Minor thesis, Dept. of Physics, University of Girona, $90 \mathrm{pp}$.

_ and M. van Weele, 2002: Effects of aerosols on UV-index. KNMI Scientific Rep. WR-2002-07.

Bais, A. F., and Coauthors, 2001: SUSPEN intercomparison of ultraviolet spectroradiometers. J. Geophys. Res., 106, 12 509-12 526.

Blumthaler, M., W. Ambach, and R. Ellinger, 1997: Increase in solar UV radiation with altitude. J. Photochem. Photobiol. Ser. B, 39, 130-134.

Bodeker, G. E., and R. L. McKenzie, 1996: An algorithm for inferring surface UV irradiance including cloud effects. $J$. Appl. Meteor., 35, 1860-1877.

— , J. C. Scott, K. Kreher, and R. L. McKenzie, 2001: Global ozone trends in potential vorticity coordinates using TOMS and GOME intercompared against the Dobson network: 1978-1998. J. Geophys. Res., 106, 23 029-23 042.

d'Almeida, G. A., P. Koepke, and E. P. Shettle, 1991: Atmo- 
spheric Aerosols: Global Climatology and Radiative Characteristics. A. Deepak Publishing, 561 pp.

Elterman, L., 1968: UV, visible, and IR attenuation for altitudes to $50 \mathrm{~km}$. Air Force Cambridge Research Laboratory Environmental Research Paper 285, AFCRL-68-0153, 49 pp.

Fioletov, V. E., J. B. Kerr, L. J. B. McArthur, D. I. Wardle, and T. W. Mathews, 2003: Estimating UV index climatology over Canada. J. Appl. Meteor., 42, 417-433.

González, J.-A., J. Mejías, and J. Calbó, 2001: Aplicación de métodos basados en medidas radiativas de banda ancha a la determinación de la turbidez atmosférica en Girona (Application of methods based on broadband radiative measurements and the atmospheric turbidity determination in Girona). El tiempo del clima (Weather and Climate), A. J. PérezCueva et al., Eds., Publicaciones de la Asociación Española de Climatología, 467-475.

Gueymard, C. A., 1998: Turbidity determination from broadband irradiance measurements: A detailed multicoefficient approach. J. Appl. Meteor., 37, 414-435.

— ity from the diffuse-beam broadband irradiance ratio. Sol. Energy, 63, 135-146.

Herman, J. R., R. L. McKenzie, S. B. Diaz, J. B. Kerr, S. Madronich, and G. Seckmeyer, 1999: Ultraviolet radiation at the Earth's surface. UNEP/WMO Scientific Assessment of the Ozone Layer: 1998, D. L. Albritton et al., Eds., Global Ozone Research and Monitoring Project Rep. 44, 9.1-9.46

Iqbal, M., 1983: An Introduction to Solar Radiation. Academic, 390 pp.

Jacobson, M. Z., 1998: Isolating the causes and effects of large ultraviolet reductions in Los Angeles. J. Aerosol Sci., 29 (Suppl.), S655-S656.

, 1999: Isolating nitrated and aromatic aerosols and nitrated aromatic gases as sources of ultraviolet light absorption. $J$. Geophys. Res., 104, 3527-3542.

Lenoble, J., 1993: Atmospheric Radiative Transfer. A. Deepak Publishing, 532 pp.

Leszczynski, K., K. Jokela, L. Ylianttila, R. Visuri, and M. Blumthaler, 1998: Erythemally weighted radiometers in solar UV monitoring: Results from the WMO/STUK intercomparison. Photochem. Photobiol., 67, 212-221.

Liley, J. B., and R. L. McKenzie, 2002: Air clarity implications for solar radiation at the surface. Proc. 16th Int. Clean Air and Environment Conf., Christchurch, New Zealand, CASANZ, 502-505.

Lorente, J., 1978: Contribución al estudio de la turbiedad atmosférica en Barcelona (Contribution to the study of atmospheric turbidity in Barcelona). Rev. Geofis., 2, 155-167.

Madronich, S., 1993: UV radiation in the natural and perturbed atmosphere. Environmental Effects of UV (Ultraviolet) Radiation, M. Tevini, Ed., Lewis Publisher, 17-69.

— , R. L. McKenzie, M. M. Caldwell, and L. O. Björn, 1994: Changes in ultraviolet radiation reaching the earth's surface. Environmental Effects of Ozone Depletion: 1994 Assessment, United Nations Environment Programme, 1-22.

McClatchey, R. A., R. W. Fenn, J. E. A. Selby, F. E. Volz, and J. S. Garing, 1972: Optical properties of the atmosphere. 3d ed. AFCRL Environmental Research Paper 411, 108 pp.

McKenzie, R. L., P. V. Johnston, M. Kotkamp, A. Bittar, and J. D. Hamlin, 1992: Solar ultraviolet spectroradiometry in New Zealand: Instrumentation and sample results from 1990. Appl. Opt., 31, 6501-6509.

- — - and G. Seckmeyer, 1997: UV spectro-radiometry in the network for the detection of stratospheric change (NDSC). Solar Ultraviolet Radiation: Modelling, Measure- ments, and Effects, C. S. Zerefos and A. F. Bais, Eds., NATO ASI Series, Vol. 1.52, Springer-Verlag, 279-287.

- K. J. Paulin, and S. Madronich, 1998: Effects of snow cover on UV radiation and surface albedo: A case study. J. Geophys. Res., 103, 28 785-28 792.

- , P. V. Johnston, D. Smale, B. Bodhaine, and S. Madronich, 2001a: Altitude effects on UV spectral irradiance deduced from measurements at Lauder, New Zealand and at Mauna Loa Observatory, Hawaii. J. Geophys. Res., 106, 22 845-22 860.

- G. Seckmeyer, A. Bais, and S. Madronich, 2001b: Satellite retrievals of erythemal UV dose compared with groundbased measurements at northern and southern mid-latitudes. J. Geophys. Res., 106, 24 051-24 062.

McKinlay, A. F., and B. L. Diffey, 1987: A reference action spectrum for ultraviolet induced erythema in human skin. Human Exposure to Ultraviolet Radiation: Risks and Regulations, W. R. Passchier and B. M. F. Bosnajakovich, Eds., Elsevier, 83-87.

Pedrós, R., M. P. Utrillas, J. A. Martínez-Lozano, and F. Tena, 1999: Values of broad band turbidity coefficients in a Mediterranean coastal site. Sol. Light, 66, 11-20.

Petters, J. L., V. K. Saxena, J. R. Slusser, B. N. Wenny, and S. Madronich, 2003: Aerosol single scattering albedo retrieved from measurements of surface UV irradiance and a radiative transfer model. J. Geophys. Res., 108, 4288, doi:10.1029/2002JD002360.

Pinazo, J. M., J. Cañada, and J. V. Boscá, 1995: A new method determine Ångstrom's turbidity coefficient: Its application for Valencia. Sol. Energy, 54, 219-226.

Radiation Commission of IAMAP, 1986: A preliminary cloudless standard atmosphere for radiation computation. Rep. WCP112, WMO/TD 24, 53 pp.

Renaud, A., J. Staehelin, C. Fröhlich, R. Philipona, and A. Heimo, 2000: Influence of snow and clouds on erythemal UV radiation: Analysis of Swiss measurements and comparison with models. J. Geophys. Res., 105, 4961-4969.

Reuder, J., and H. Schwander, 1999: Aerosol effects on UV radiation in nonurban regions. J. Geophys. Res., 104, 4065-4077.

Schmalwieser, A. W., and G. Schauberger, 2001: A monitoring network for erythemally-effective solar ultraviolet radiation in Austria: Determination of the measuring sites and visualisation of the spatial distribution. Theor. Appl. Climatol., 69, 221-229.

_ and Coauthors, 2002: Worldwide forecast of the biologically effective UV radiation: UV index and daily dose. Ultraviolet Groundand Space-based Measurements, Models, and Effects. J. R. Slusser, J. R. Herman, and W. Gao, Eds., International Society for Optical Engineering (SPIE Proceedings Vol. 4482), 259-264.

Schmucki, D., and R. Philipona, 2001: UV radiation in the Alps: Altitude effect. Extended Abstracts, EGS XXVI General Assembly, Nice, France, European Geophysical Society, Vol. 3, CD-ROM.

Vanicek, K., T. Frei, Z. Litynska, and A. Schmalwieser, 2000: UV index for the public. Working Group 4 of the COST-713 Action "UVB Forecasting." [Available online at http:// www.lamma.rete.toscana.it/uvweb/.]

Verdebout, J., 2000: A method to generate surface UV radiation maps over Europe using GOME, Meteosat, and ancillary data. J. Geophys. Res., 105, 5049-5058.

Weihs, P., and Coauthors, 2002: Effective surface albedo due to snow cover of the surrounding area. Ultraviolet Ground-and Space-based Measurements, Models, and Effects. J. R. Slusser, J. R. Herman, and W. Gao, Eds., International Society for Optical Engineering (SPIE Proceedings Vol. 4482), 152-159.

Zaratti, F., R. N. Forno, J. Garcia Fuentes, and M. F. Andrade, 2003: Erythemally weighted UV variations at two high-altitude locations. J. Geophys. Res., 108, 4263-4268. 